\title{
Prevalence of gestational choriocarcinoma in a parous population in ten years
}

\author{
Fatma Al Wahaibi ${ }^{1}$, Vaidyanathan Gowri ${ }^{1 *}$, Suad Al Kharusi ${ }^{2}$, Thuria Al Rawahi ${ }^{3}$
}

\begin{abstract}
${ }^{1}$ Department of Obstetrics and Gynecology, Sultan Qaboos University, Muscat, Oman
${ }^{2}$ Department of Medical Oncology, Royal hospital, Muscat, Oman

${ }^{3}$ Department of Obstetrics and Gynecology, Royal Hospital, Muscat, Oman
\end{abstract}

Received: 05 July 2020

Accepted: 03 August 2020

*Correspondence:

Dr. Vaidyanathan Gowri,

E-mail: gowrie61@ @otmail.com

Copyright: () the author(s), publisher and licensee Medip Academy. This is an open-access article distributed under the terms of the Creative Commons Attribution Non-Commercial License, which permits unrestricted non-commercial use, distribution, and reproduction in any medium, provided the original work is properly cited.

\section{ABSTRACT}

Background: Choriocarcinoma is a rare disease with varying incidence in different parts of the world. Asian, American Indian and Africans are quoted to be at a higher risk. There are no epidemiological data from Middle East and hence authors studied the prevalence of choriocarcinoma in Oman, a Middle East nation with a high parity.

Methods: This is a retrospective, descriptive, observational study done at tertiary care hospital; Royal Hospital from Jan 2010 to Dec 2019. Since all women are referred to a single center from all over the country, authors believe all cases are included over ten years.

Results: There were 22 patients and the prevalence were 1 in 36966 live births. The main presenting symptom was abnormal uterine bleeding and all were gestational type of choriocarcinoma. Median gravidity was 6 and median parity was 5 . Almost $80 \%$ received chemo as their risk scoring was more than 7 and one woman died.

Conclusions: The prevalence of choriocarcinoma was much similar to Europe and USA though the median gravidity and parity was high. Clinical features were comparable to the literature and management protocols were as per international recommendations.

Keywords: Choriocarcinoma, Parity, Prevalence

\section{INTRODUCTION}

Choriocarcinoma is a type of gestational trophoblastic neoplasia which can follow any form of pregnancy, such as hydatidiform moles, abortion, term pregnancy or ectopic gestation. ${ }^{1}$ It is a rare disease. In Europe and North America, about 1 in 40,000 pregnant patients and 1 in 40 patients with hydatidiform moles develop choriocarcinoma. ${ }^{2,3}$ In Southeast Asia and Japan, 9.2 in 40,000 pregnant women and 3.3 in 40 patients with hydatidiform moles are likely to develop choriocarcinoma. ${ }^{2}$ In China, 1 in 2882 pregnant women apparently develop choriocarcinoma. ${ }^{3}$ This correlates with an increased risk for development of choriocarcinoma in Asian, American Indian, and African American women. ${ }^{2}$ Other risk factors include prior complete hydatidiform mole (a 100-fold increased risk), advanced age, long-term oral contraceptive use, and blood group A. ${ }^{2}$

It is highly aggressive, malignant trophoblastic neoplasm that can be gestational or non-gestational in origin. Accurate discrimination between these two subtypes, the causative pregnancy type, and the pregnancy-to-treatment interval for gestational choriocarcinoma are vital for clinical management. ${ }^{4}$

Choriocarcinoma has the tendency to widespread local dissemination and distant metastases. Pelvis is one of the initial sites of metastasis. High mortality rate has been observed in patients with extra pelvic metastasis. Unfortunately, the patients with choriocarcinoma despite 
widespread disease might have no specific symptoms, but it should be kept in mind that early diagnosis and appropriate chemotherapy could be curable..$^{5,6}$

Although only 0.76 to $4 \%$ cases of choriocarcinoma develop in ectopic locations, they are usually more aggressive and associated with distant metastasis. ${ }^{7,8}$ It can develop anytime between 5 weeks and 15 years after gestation or even after menopause. ${ }^{9,10}$ Approximately $30 \%$ cases of choriocarcinoma have metastatic disease at the time of diagnosis. Lungs $(80 \%)$ are the most common site of metastasis, followed by vagina $(30 \%)$ and liver $(10 \%)$. Metastatic choriocarcinoma involves the brain in $3-28 \%$ of patients. $^{11}$ The clinical presentation of choriocarcinoma is so much varied that every case may be one of its kinds and thus can be a diagnostic challenge.

Early diagnosis and prompt initiation of chemotherapy is a well-known determinant of prognosis of choriocarcinoma. A knowledge regarding the variations from its classic clinical presentation are, therefore, a must to any practicing clinician. The main aim of this research is to present an epidemiological study from a parous population, in Oman over the last 10 years 2010-2019. This is possible as all the cases are referred to one institute only.

\section{METHODS}

This is a retrospective, descriptive, observational study done at tertiary care hospital; Royal Hospital from January 2010 to December 2019, for 10 years.

\section{Inclusion criteria}

All cases with confirmed diagnosis of gestational choriocarcinoma clinically and histopathology were included.

\section{Exclusion criteria}

Women with non-gestational choriocarcinoma placental site trophoblastic tumor (PSTT), and epithelioid trophoblastic tumor (ETT) were excluded.

This study looked into different aspects including the demographic characteristics like age, gravidity, parity and miscarriages clinical presentation and physical signs. Authors also studied the management, treatment and follow up path over the study period. Medical management including chemotherapy, surgical management and radiation therapy if done were obtained from medical records. Results are presented as simple descriptive statistics as frequency of occurrence, mean \pm SD and percentages. All women had ultrasound of the pelvis for imaging and chest X-ray and other modalities like CT abdomen and pelvis, MRI of the involved organs if indicated.
Ethical approval was obtained from the hospital ethical committee. Data collected from the hospital electronic records. All cases were referred from all over the country to single institute (Royal hospital) and hence authors believe all cases are included over 10 years.

\section{RESULTS}

Authors had a total of 22 cases over the ten-year period. The incidence is 1 in 36966 live births and 1 in 236 women with hydatidiform mole developed choriocarcinoma. All cases were gestational. Mean age of the women was $39.77 \pm 7.6$ years with a median gravidity of 6 and median parity of 5 . About $60 \%$ women were in the age group of $20-40$ years and $36.4 \%$ in the age group of 41-50 years. Others were more than 50 years old. About 55\% were of parity 1-6 and 9\% had more than 11 deliveries. The commonest blood group was $\mathrm{O}$ rhesus positive $(45.5 \%)$ followed by B rhesus positive $(22.7 \%)$. Only $23 \%$ had history of previous molar pregnancy, $63 \%$ had a miscarriage and the rest after a term pregnancy. Presenting symptoms are mentioned in Table 1 and site of metastases in Table 2.

Table 1: Presenting symptoms.

\begin{tabular}{|lll|}
\hline Symptoms & Frequency & $\%$ \\
\hline Abnormal uterine bleeding & 16 & 72.7 \\
\hline Abdominal pain & 2 & 9.1 \\
\hline $\begin{array}{l}\text { Abnormal bleeding with } \\
\text { nausea and vomiting }\end{array}$ & 1 & 4.5 \\
\hline Not available in records & 3 & 13.6 \\
\hline
\end{tabular}

Table 2: Sites of metastases.

\begin{tabular}{|c|c|c|}
\hline Site & Frequency & $\%$ \\
\hline Genital organ & 3 & 13.6 \\
\hline Lung & 10 & 45.5 \\
\hline Brain & 2 & 9.1 \\
\hline Lung, brain and adrenals & 1 & 4.5 \\
\hline Nil & 6 & 27.3 \\
\hline Total & 22 & 100 \\
\hline
\end{tabular}

Table 3: Type of chemotherapy.

\begin{tabular}{|lll|}
\hline Chemotherapy & Frequency & $\%$ \\
\hline Methotraxate + folinic acid & 1 & 4.5 \\
\hline EMACO & 11 & 50 \\
\hline EMACO+MTX & 2 & 9.1 \\
\hline Piclataxel/Etopside & 1 & 4.5 \\
\hline $\begin{array}{l}\text { Multiple(EMACO/etopside/ } \\
\text { piclataxel/cisplatin) }\end{array}$ & 2 & 9.1 \\
\hline Not documented & $1^{*}$ & 4.5 \\
\hline Not applicable & $4^{* *}$ & 18.2 \\
\hline Total & 22 & 100 \\
\hline
\end{tabular}

*syrian patients went back home and had chemo there. **Two did not need chemo, one lost for follow-up and one refused chemo. 
Table 4: Survival and type of chemotherapy.

\begin{tabular}{|lll|}
\hline Type of chemo & Disease free survival & Recurrence \\
\hline EMA-CO & 9 & 2 \\
\hline EMACO-MTX & 2 & 0 \\
\hline Multiple (EMACO, taxol, etoposide, cisplatin) & 0 & 2 \\
\hline Methotrexate+folinic acid & 1 & 0 \\
\hline Etoposide+paclitaxol & 1 & 0 \\
\hline
\end{tabular}

The type of chemotherapy and survival after chemotherapy is presented in table 3 and table 4 respectively.

All cases were gestational choriocarcinoma. One of them presented in the postmenopausal period, almost ten years after the last child birth. About $55 \%$ had a $\beta$ human chorionic gonadotropin (hCG) value of more than 20,000 IU and for others it ranged from 1000-20,000. Most of the women had a risk score of 7 or more based on the WHO risk prognostic scoring system.

Around $45 \%$ of the patients received chemotherapy and $36 \%$ had both hysterectomy and chemotherapy. Only two patients $(9.1 \%)$ had hysterectomy and did not require chemotherapy as $\beta$-hCG was normal on follow-up for 3 years post op. Majority of the cases received EMACO chemotherapy $(50 \%)$ with a median of 6 cycles. $\beta$-hCG normalized after the $4 \pm 1.9$ cycles of chemotherapy. The mean time to start chemotherapy from diagnosis was just under four weeks in most women.

There was one mortality of the 22 women $(4.5 \%)$. Four women had recurrent disease and the details are as below.

Number 1 had recurrence in lung, brain and adrenal in five months, went abroad then had some cycles of chemo and hysterectomy, planned for bone marrow transplant.

Number 2 recurrence after five years unknown location and she went abroad.

Number 3 recurrence after three years in uterus, had another cycles of chemo then hysterectomy then had bone marrow transplant in Turkey.

Number 4 recurrence in 5 months and had chemo and died of severe neutropenia.

\section{DISCUSSION}

There are two types of choriocarcinoma, gestational and non -gestational. Non gestational choriocarcinoma arises from pluripotent cells and mostly in gonads. Gestational can arise following a miscarriage, molar pregnancy and term pregnancy. ${ }^{12}$ Though the incidence in Japan and South east Asia is 9.2 in 40,000, the incidence in China is very high., ${ }^{2,3}$ It was our interest to see a ten year prevalence of choriocarcinoma in a Middle East country with a population of about 2.5 million natives and the average parity is about 5 . This study was possible as all cases from all over the country get referred to one institute, once the diagnosis is made.

The incidence of choriocarcinoma after molar pregnancy appears to be different from the report by Nagan et al. ${ }^{13}$ This may be explained by the fact that the products of conception following medical termination of pregnancy may not always be sent for histology. Abnormal uterine bleeding is the commonest presenting symptom in this series as reported by others, followed by abdominal pain and mass in the vagina. ${ }^{14}$

None of this study patients presented with symptoms of secondaries, like hemoptysis or convulsions. The commonest site of secondaries was lungs followed by pelvis and brain. This is slightly different from the described literature. ${ }^{15}$ Much contrary to the report by Alteiri et al the commonest blood group in this study series was "O" and not "A". ${ }^{16}$

There was one mortality of the 22 women (4.5\%). She had choriocarcinoma arising from an ectopic pregnancy in fallopian tube along with a normal intrauterine pregnancy (heterotopic pregnancy). After salpingectomy pregnancy proceeded to 32 weeks and she was delivered by cesarean section. Though she responded well to four cycles of chemotherapy after delivery, she died due to neutropenia five months from the diagnosis. This is an extremely rare case of choriocarcinoma from heterotopic pregnancy.

Regarding chemotherapy most patients received standard of care which was combination chemotherapy as per their risk grading. ${ }^{17,18}$ There was recurrence in four women and this occurred from five months to five years from the initial disease. The recurrence rate was higher than quoted in the literature as some of them were not compliant and travelled abroad for treatment.

\section{CONCLUSION}

In conclusion, the main risk factors in this series were, $50 \%$ women were older than 40 years of age and the mean parity was five. The strength of this study is the referral to single center in the whole country and availability of almost all records. The weakness is that it is retrospective and information on one or two patients is 
missing. The incidence of choriocarcinoma is almost similar to the western world in spite of high mean gravidity and parity in this part of the world.

Funding: No funding sources

Conflict of interest: None declared

Ethical approval: The study was approved by the Institutional Ethics Committee

\section{REFERENCES}

1. Mangili G, Lorusso D, Brown J, Pfisterer J, Massuger L, Vaughan M, et al. Trophoblastic disease review for diagnosis and management a joint report from the international society for the study of trophoblastic disease, european organization for the treatment of trophoblastic disease, and the gynecologic cancer inter group. Int J Gynecol Cancer. 2014;24:S109-16.

2. Lurain JR. Gestational trophoblastic disease I: epidemiology, pathology, clinical presentation and diagnosis of gestational trophoblastic disease, and management of hydatidiform mole. Am J Obstet Gynecol. 2010;203(6):531-9.

3. Zhang W, Liu B, Wu J, Sun B. Hemoptysis as primary manifestation in three women with choriocarcinoma with pulmonary metastasis: a case series. J Med Case Repo. 2017;11(1):1-5.

4. Cheung AN, Zhang HJ, Xue WC, Siu MK. Pathogenesis of choriocarcinoma: clinical, genetic and stem cell perspectives. Future Oncol. 2009;5(2):217-31.

5. Feng F, Xiang Y. Surgical management of chemotherapy-resistant gestational trophoblastic neoplasia. Expert Rev Anticancer Ther. 2010;10(1):71-80.

6. Lurain JR, Singh DK, Schink JC. Role of surgery in the management of high-risk gestational trophoblastic neoplasia. J Reprod Med. 2006;51(10):773-6.

7. Chen MJ, Yang JH, Lin MC, Ho HN, Yang YS. An unusual gestational choriocarcinoma occurring primarily in the surface of subserous leiomyoma. BJOG. 2004;111:188e90.

8. Salleh S, Arthrur I. Persistent peritoneal trophoblastic implantation following salpingotomy, salpingectomy and methotrexate for ectopic pregnancy. Gynecol Surg. 2005;2:195e6.

9. Hassadia A, Kew FM, Tidy JA, Wells M, Hancock BW. Ectopic gestational trophoblastic disease: a case series review. J Reprod Med. 2012;57:297e300.
10. Soper JT, Mutch DG, Schink JC. American college of obstetricians and gynaecologists diagnosis and treatment of gestational trophoblastic disease; ACOG practice bulletein no. 53. Gynecol Oncol. 2004;93:575e85.

11. Berkowitz RS, Goldstein DP. Gestational Trophoblastic Disease. In: Berek J, editor. Berek and Novak's Gynecology. Philadelphia: Lippincott Williams and Wilkins; 2007:1581e603.

12. Stockton L, Green E, Kaur B, De Winton E. Nongestational choriocarcinoma with widespread metastases presenting with type 1 respiratory failure in a 39-year-old female: case report and review of the literature. Case Rep Oncol. 2018;11(1):1-5.

13. Ngan S, Seckl MJ. Gestational trophoblastic neoplasia management: an update. Curr Opin Oncol. 2007;19:486.

14. Ngan HYS, Seckl MJ, Berkowitz RS, Xiang Y, Golfier F, Sekharan PK, et al. Update on the diagnosis and management of gestational trophoblastic disease. Int $\mathrm{J}$ Gynaecol Obstet. 2018;143 Suppl 2:79.

15. Berkowitz RS, Goldstein DP. Current management of gestational trophoblastic diseases. Gynecol Oncol. 2009; $112: 654$.

16. Altieri A, Franceschi S, Ferlay J, Smith J, La Vecchia C. Epidemiology and aetiology of gestational trophoblastic diseases. The Lancet. Oncology. 2003;4(11):670-8.

17. Sita-Lumsden A, Short D, Lindsay I, Sebire NJ, Adjogatse D, Seckl MJ, et al. Treatment outcomes for 618 women with gestational trophoblastic tumours following a molar pregnancy at the Charing Cross Hospital, 2000-2009. Br J Cancer. 2012;107(11):1810-4.

18. McNeish IA, Strickland S, Holden L, Rustin GJ, Foskett M, Seckl MJ, et al. Low-risk persistent gestational trophoblastic disease: outcome after initial treatment with low-dose methotrexate and folinic acid from 1992 to 2000. J Clin Oncol. 2002;20:1838.

Cite this article as: Wahaibi FA, Gowri V, Kharusi SA, Rawahi TA. Prevalence of gestational choriocarcinoma in a parous population in ten years. Int J Reprod Contracept Obstet Gynecol 2020;9:3537-40 